\title{
Rock Preference of Planulae of Jellyfish Aurelia aurita (Linnaeus 1758) for Settlement in the Laboratory
}

\author{
Won Duk Yoon ${ }^{1 *}$, Sung-Hwan Choi ${ }^{1,2}$, Changhoon Han ${ }^{1}$, and Won Gyu Park ${ }^{2}$ \\ ${ }^{1}$ Jellyfish Monitoring and Countermeasure Center/Fisheries and Ocean Information Division, NFRDI, Busan 619-705, Korea \\ ${ }^{2}$ Department of Marine Biology, College of Fisheries Sciences, Pukyong National University, Busan 609-737, Korea
}

Received 25 February 2014; Revised 19 May 2014; Accepted 16 June 2014

(C) KSO, KIOST and Springer 2014

\begin{abstract}
Planulae of Aurelia aurita were exposed to 11 types of rocks (basalt, gabbro, granite, rhyolite, sandstone, limestone, conglomerate, gneiss, quartzite, marble and schist) to examine their attachment preference among rock material and position. Numbers of attached polyps was the highest on marble and the least on limestone. Their preference with regard to settling position was the same among the rocks, showing the highest density of polyps on the underside (88.5\%) compared to upper (23.6\%) and perpendicular sides $(10.3 \%)$ of rock. The results showed that while position preference is more important than rock property, higher numbers of polyps were observed in rocks with a medium surface hardness.
\end{abstract}

Key words - Aurelia aurita, planula, polyp, settlement, rock, substrate

\section{Introduction}

The moon jelly (Aurelia aurita) is one of the most widely distributed species of jellyfish (Arai 1997). In Korean waters, A. aurita has bloomed in the southwestern coast (Masan Bay) since the late 1970s, and in the mid-eastern Yellow Sea (Sihwa Lake) in the late 1990s, and has extended its presence recently into most of eastern Yellow Sea and Korean southern coast. Recent investigations to learn about the areas of mass habitation of $A$. aurita's polyp revealed that they are found at man-made marine structures, such as dykes, harbors, cages and facilities of aquaculture, and natural rocks. At present, estimates of polyps of $A$. aurita exceed 100 million at 7 areas where the coastal lines were strongly modified and explored with heavy eutrophication (Chungchongnam-do

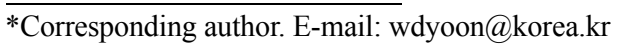

2011; Jeollabuk-do 2011; MIFAFF 2012). The blooms of $A$. aurita start in the areas of mass habitation of polyps, then, with coastal currents, move into all Korean coastal waters, including the western East Sea, causing huge economic damage to fisheries and nuclear power plants by clogging cooling-water intake screens (MLTM 2009).

Scyphozoan planulae prefer the undersides of substrates (Brewer 1978; Willcox et al. 2008), and polyps, including A. aurita's, have been found on natural substrate, such as algae, mussel shells, stones, and others as well as on artificial substrates, such as concrete, plastic, glass, and floating docks in marinas (Miyake et al. 2002; Willcox et al. 2008; Hoover and Purcell 2009; Korsun et al. 2012; Janßen et al. 2013). Among these materials, the preference of planulae with regard to settlement was strong for artificial substrate to natural one (Holst and Jarms 2007; Hoover and Purcell 2009).

There is little knowledge about the reason why planulae attach themselves more often to specific substrates than others. Hoover and Purcell (2009) proposed softness and variation in texture may be the major factors to determine the substrate preference of planula settlement. Previous tests for substrate preference have been made by comparing totally different kinds of matter such as concrete, plastic, glass and so on.

Rocks are common materials in both nature and artificial constructions where the jellyfish polyps have been often observed. We exposed planulae of Aurelia aurita to a set of various rocks of different texture and composition in the hope of clarifying their preference for rock substrates with different characteristics in the laboratory. We also simultaneously 
determined the preferred position of planula settlement, classifying those positions into the upper side, underside and perpendicular sides.

\section{Materials and Methods}

Rocks used in this experiment were purchased from Ward's Natural Science (No.45-3130) and consisted of the most common rocks on earth (igneous rock: basalt, gabbro, granite, rhyolite; sedimentary rock: sandstone, limestone, conglomerate; metamorphic rock:gneiss, quartzite, marble and schist). The rocks were cut into rectangular form (ca. 5, 2 and $1.5 \mathrm{~cm}$ in length, width and height, respectively), unpolished, and autoclaved at $121^{\circ} \mathrm{C}$ for $15 \mathrm{~min}$. Each set was submerged into 51 jars filled with GF/F filtered seawater. Each rock was bound with fishing line and suspended horizontally at $1.5 \mathrm{~cm}$ from the bottom of a jar. The jars were gently aerated for 10 days to let the biofilm develops.

Planulae of Aurelia aurita were acquired from one mature female (bell diameter: ca. $20 \mathrm{~cm}$ ) collected in Masan Bay, Korea in October, 2012. The planulae were pipet-collected from the arm pouches and kept in distilled water pre-washed jars filled with seawater of ca. 34 psu. Upon starting, seawater of the jar containing planulae was well mixed and divided into five portions and each portion then was added into the jars with sets of 11 rocks. The experiment was conducted for 5 days at ambient room temperature (seawater temperature: 9.8-15.3 $\left.3^{\circ} \mathrm{C}\right)$, dim natural sunlight $(<500 \mathrm{lux})$, and without water exchange, food, or air supply.

Data were first verified for the normal distribution and homogeneity of variances (Levene test), and subjected to one-way ANOVA (SPSS. Ver. 10) to determine the relationship among preferences for rocks and sides attaching position by planulae.

\section{Result}

Planulae settlement varied among the rocks (Fig. 1) and was statistically different (Table 1); marble was the most $(21.5 \%$, average No. $=32.4$ polyps $)$ and the limestone the least preferred rock $(2.4 \%$, average No. $=3.6$ polyps $)$. Sum of polyps found on the marble, gabbro, sandstone and conglomerate represented ca. $62 \%$ of total. Difference among the rock types was not observed (average polyp no: 14.2, 12.5, 14.1 polyps for igneous, sedimentary, and metamorphic rock, respectively).

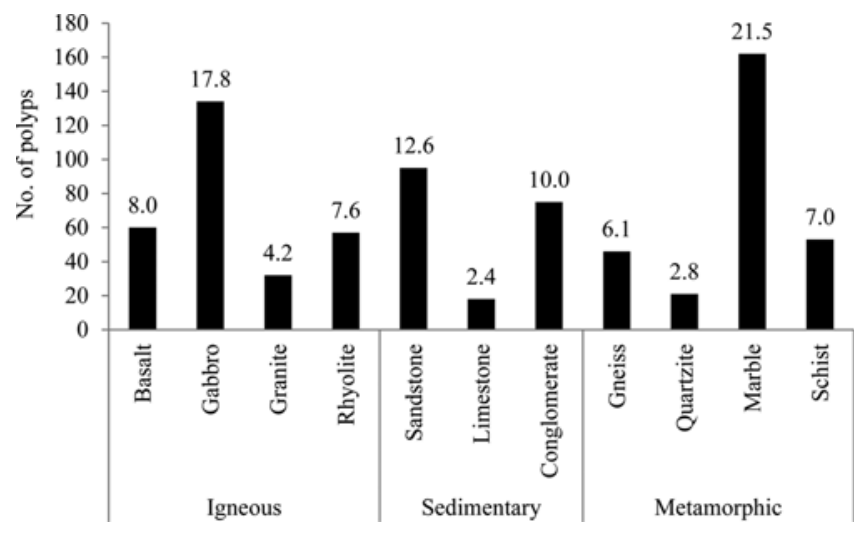

Fig. 1. Number of polyps found along the rocks with percentage above the vertical bar

Table 1. Result of ANOVA on rock (a) and side (b) preference of A. aurita's planula

\begin{tabular}{ccccc}
\hline \hline a) Source of variation & SS & df & MS & P \\
\hline Groups & 4173.345 & 10 & 417.335 & 0.013 \\
Error & 6916.400 & 44 & 157.191 & \\
Total & 11089.745 & 54 & & \\
\hline b) Source of variation & SS & df & MS & P \\
\hline Groups & 1625.018 & 2 & 812.509 & 0.000 \\
Error & 7711.564 & 162 & 47.602 & \\
Total & 9336.582 & 164 & & \\
\hline
\end{tabular}

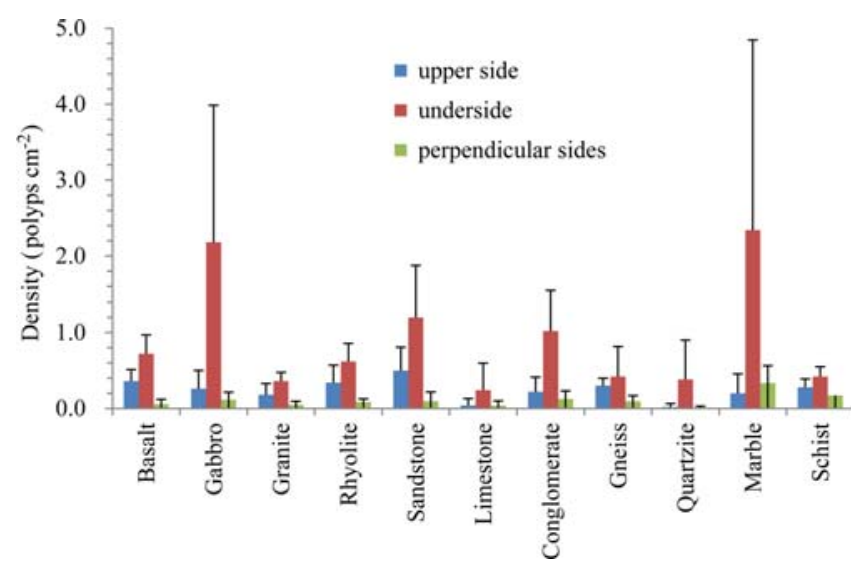

Fig. 2. Number of polyps found upper, underside and perpendicular side of rocks. Vertical bars indicate SE

Planulae attached and metamorphosed more at the underside than at the upper or perpendicular sides of rocks[no. of attached polyps: $495(88.5 \%), 135(23.6 \%)$ and $123(10.3 \%)$ polyps for underside, upper and perpendicular sides, respectively, Fig. 2, Table 1], although the surface of perpendicular side areas was 2.1 times larger than that of the upper or underside. Between the upper and perpendicular sides, preference varied little. 


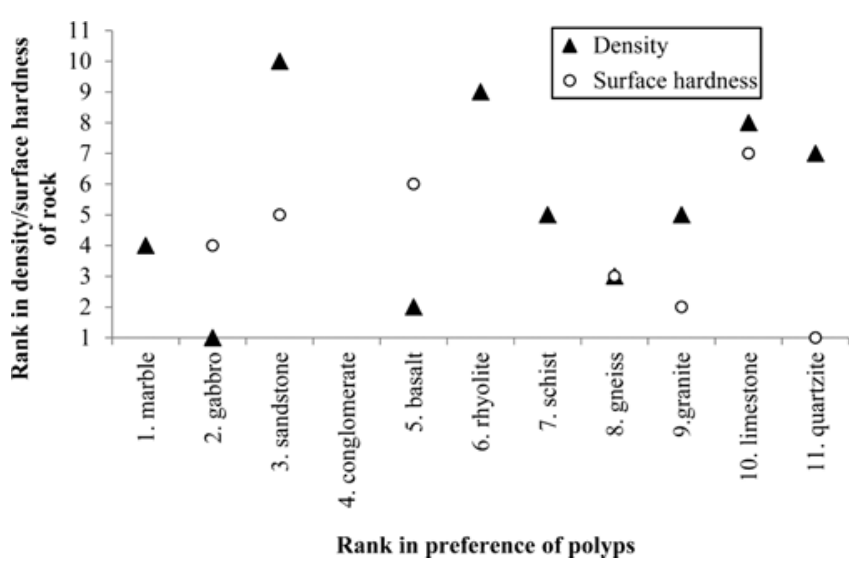

Fig. 3. Plot between rank in rock preference of polyps and ddensity (D) and surface hardness ( $\mathrm{SH}$ ) of rocks

Planulae seemed have no preference for the specific density of rock (http://geology.about.com/cs/rock_types/a/ aarockspecgrav.htm), while they are more likely to favor rock surfaces of medium hardness (Yarali and Soyer 2013) (Fig. 3).

\section{Discussion}

In Aurelia aurita, fertilized eggs move to brood chambers along the edges of oral arms and metamorphose into planulae. Fully grown planulae slide out of the brood chamber, swim freely in the water column, and when they find a substrate, they slide over or move up and down, seeking an appropriate substrate to settle down on (Arai 1997). Even though scyphozoan planulae are able to attach themselves to almost all underwater materials, they prefer artificial materials to natural ones (Lotan et al. 1992; Pitt 2001; Holst and Jarms 2007), and furthermore, among the artificial substrates, preference varied; plastic was the most preferred and glass (Holst and Jarms 2006), rubber and treated wood the least (Hoover and Purcell 2009). Whatever the substrate is, planulae settle more at the underside than the upper or perpendicular sides of the materials (Brewer 1978; Holst and Jarms 2007). The advantages of such up-side down settlement are probably avoidance from siltation (Arai 1997), and solar irradiation and predation (Svane and Dolmer 1995), anaerobic condition and increase in food availability (Brewer 1976), and to facilitate defecation (Holst and Jarms 2007).

Natural conditions and texture peculiarity of substrate material seem to affect the settlement of planulae. Accordingly, Hoover and Purcell (2009) proposed softness and variation in texture as the determinant factors. In this regard the present study provides valuable insights. The tested rocks were different in density and surface hardness. Among the rocks, quartzite is mainly composed of quartz which is one of the hardest matters on earth (7 in Mohs hardness scale). Granit is coarsegrained rock containing 20-60\% of quartz (Wilson 1995), the second hardest rock in our experiment. Gabbro and basalt are calcium-plagioclase dominant rocks of coarse- and finegrained rock, respectively. Igneous rocks like basalt and granite metamorphose into schist and gneiss, respectively, and the sedimentary rocks like sandstone and limestone into quartzite and marble, respectively. After metamorphosing, they should become more compact in texture and gain more surface hardness. Rock density and the surface hardness were not significantly related with planula settlement, however the rocks of medium surface hardness are assumed to be more preferred for planula settlement. As the number of the experimental samples might not be enough in this study, and further studies are required.

Upon settlement, planulae would seek, by instinct, the most energy saving site, which seems the underside in order to maximize feeding with fully extended tentacles and to ease defecation. After successful settlement and survival, the prosperity of polyps at that site, and eventual jellyfish blooms, should depend on micro-scale shear stress (Keen 1987), stability of the substrate (Toyokawa et al. 2011), and competition with other sessile benthic organisms (Lotan et al. 1992). Strength and means of attachment of planulae and polyps onto substrate are not fully understood, and need to be studied further.

\section{Acknowledgement}

This study was supported by 'Jellyfish monitoring and mitigation (14-OE-14)' funded by National Fisheries Research and Development Institute, Korea, and 'Management of marine organisms causing ecological disturbance and harmful effects' by Korea Institute of Marine Science and Technology Promotion/ Ministry of Oceans and Fisheries, Korea.

\section{References}

Arai MN (1997) A functional biology of Scyphozoa. Chapman \& Hall, $316 \mathrm{p}$

Brewer RH (1976) Larval settling behavior in Cyanea capilluta (Cnidaria: Scyphozoa). Biol Bull 150:183-199 
Brewer RH (1978) Larval Settlement Behavior in the Jellyfish Aurelia aurita (Linnaeus) (Scyphozoa: Semaeostomeae). Estuaries 1(2):120-122

Chungchongnam-do (2011) Investigation and countermeasures on jellyfish polyps in Korean waters. Chungchongnam-do, 90 $\mathrm{p}$ (in Korean)

Holst S, Jarms G (2007) Substrate choice and settlement preferences of planula larvae of five Scyphozoa (Cnidaria) from German Bight, North Sea. Mar Biol 151:863-871

Hoover RA, Purcell JE (2009) Substrate preferences of scyphozoan Aurelia labiata polyps among common dock-building materials. Hydrobiol 616:259-267

Janßen H, Augustin CB, Hinrichsen HH, Kube S (2013) Impact of secondary hard substrate on the distribution and abundance of Aurelia aurita in the western Baltic Sea. Mar Pollut Bull 75:224-234

Jeollabuk-do (2011) Investigation and countermeasures on jellyfish polyps in Korean waters. Jeollabuk-do, 90 p (in Korean)

Keen SL (1987) Recruitment of Aurelia aurita (Cnidaria: Scyphozoa) larvae is position-dependent, and independent of conspecific density, within a settling surface. Mar Ecol-Prog Ser 38:151-60

Korsun S, Fahrni JF, Pawlowski J (2012) Invading Aurelia aurita has established scyphistoma populations in the Caspian Sea. Mar Biol 159:1061-1069

Lotan A, Ben-Hillel R, Loya Y (1992) Life cycle of Rhopilema nomadica: a new immigrant scyphomedusan in the Mediterranean. Mar Biol 112:237-242
LucasCH (2001) Reproduction and life history strategies of the common jellyfish, Aurelia aurita, in relation to its ambient environment. Hydrobiol 451:229-246

MIFAFF (Ministry of Food, Agriculture, Forestry and Fisheries, Korea) (2012) Investigation and countermeasures on jellyfish polyps in Korean waters. Gyeongsangnam-do, 119 p (in Korean)

Miyake H, Terazaki M, Kakinuma Y (2002) On the polyps of the common jellyfish Aurelia aurita in Kagoshima Bay. J Oceanogr 58:451-459

MLTM (Ministry of Land, Transport and Maritime Affairs, Korea) (2009) Preventing damages from harmful jellyfish, 225 p (in Korean)

Pitt KA (2000) Life history and settlement preferences of the edible jellyfish Catostylus mosaicus (Scyphozoa: Rhizostomeae). Mar Biol 136:269-279

Toyokawa M, Anki K, Yamada S, Yasyda A, Mutata Y, Kikuchi T (2011) Distribution of ephyrae and polyps of jellyfish Aurelia aurita (Linnaeus 1758) sensu lato in Mikawa Bay, Japan. J Oceanogr 67:209-218

Willcox S, Moltschaniwskyj NA, Crawford C (2008) Population dynamics of natural colonies of Aurelia sp. scyphistomae in Tasmania, Australia. Mar Biol 154:661-670

Wilson JR (1995) A collector's guide to rock, mineral, and fossil localities of Utah. Utah Geological Survey, $148 \mathrm{p}$

Yarali O, Soyer E (2013) Assessment of relationships between drilling rate index and mechanical properties of rocks. Tunn Undergr Space Technol 33:46-53 